Portland State University

PDXScholar

\title{
The Role of Divalent Metals in DNA Replication During Periods of Oxidative Stress
}

Corinne Hutfilz

Portland State University

Follow this and additional works at: https://pdxscholar.library.pdx.edu/honorstheses

\section{Let us know how access to this document benefits you.}

\section{Recommended Citation}

Hutfilz, Corinne, "The Role of Divalent Metals in DNA Replication During Periods of Oxidative Stress" (2017). University Honors Theses. Paper 463.

https://doi.org/10.15760/honors.463

This Thesis is brought to you for free and open access. It has been accepted for inclusion in University Honors Theses by an authorized administrator of PDXScholar. Please contact us if we can make this document more accessible: pdxscholar@pdx.edu. 
The Role of Divalent Metals in DNA Replication During Periods of Oxidative Stress

by

Corinne Hutfilz

\begin{abstract}
An undergraduate honors thesis submitted in partial fulfillment of the requirements for the degree of

Bachelor of Science

in

University Honors

and
\end{abstract}

Biology \& Philosophy

Thesis Adviser

Justin Courcelle

Portland State University

2017 


\section{Table of Contents}

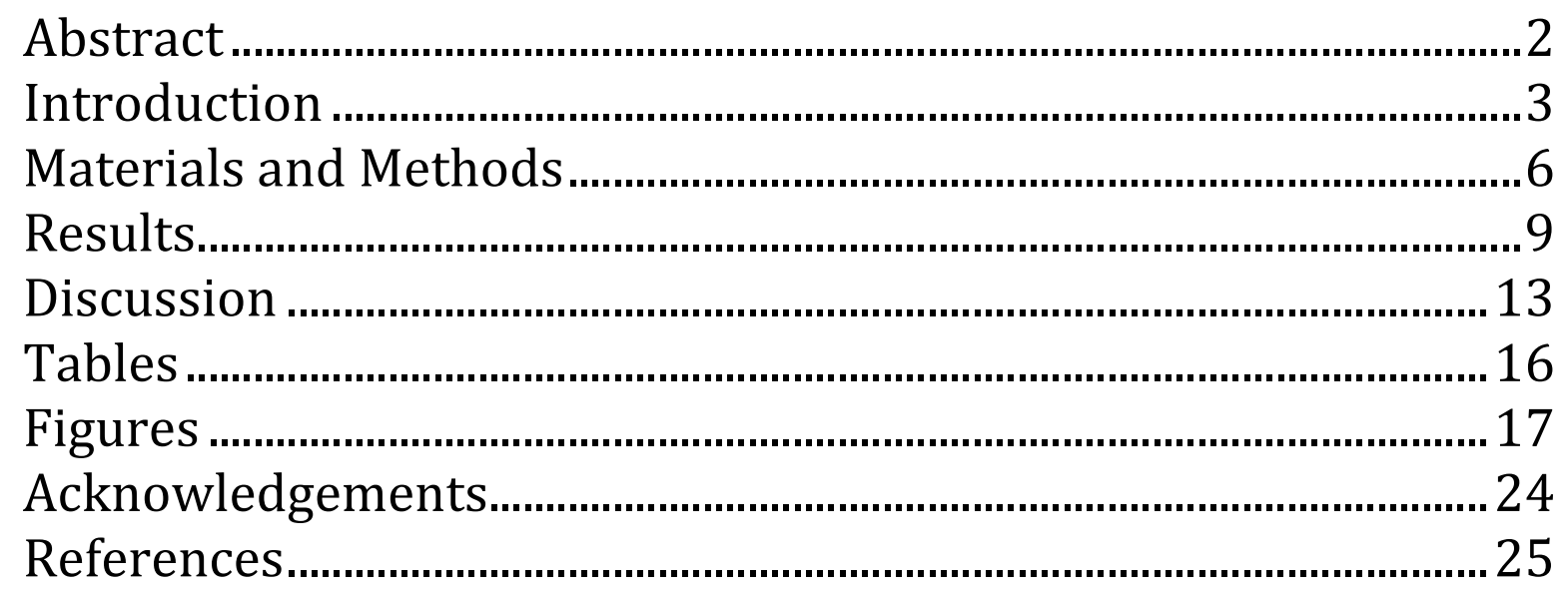




\begin{abstract}
$\underline{\text { Abstract }}$
Oxygen radicals are a prominent and ever-present threat to all organisms. Reactive oxygen species (ROS) arise through regular aerobic metabolism and iron-catalyzed degradation of hydrogen peroxide or other exogenous sources such as UV radiation (Fridovich, 1995; Rowe et al., 2008). ROS react with DNA to form a variety of base modifications, single strand breaks (SSBs), or even double strand breaks (DSBs) when clustered oxidative lesions are formed (Lindahl, 1993; Semenenko and Stewart, 2005; Semenenko et al., 2005). Many of these DNA lesions are known to block DNA polymerases, preventing replication and subsequent cell division if not repaired. Divalent metals such as iron and manganese play an important role in the cellular response to oxidative challenges and are required as cofactors by many enzymes. However, how these metals affect the ability and fidelity of replication after oxidative challenge is not known. Here we characterized how DNA replication recovers following oxidative damage under conditions where the cell has access to iron or manganese. We show that although the presence of either metal did not affect survival, the presence of manganese promoted rapid recovery of DNA replication after oxidative challenge; while cells cultured with iron or no metal failed to resume DNA synthesis, the recovery that occurred in the presence of manganese was associated with elevated rates of mutagenesis, and this mutagenesis was specific to oxidative DNA damage. Finally, we found that this mutagenesis did not require the presence of RecF, but was partially reduced in the absence of translesion polymerases Pol II, Pol IV and PolV.
\end{abstract}




\section{$\underline{\text { Introduction }}$}

Some DNA lesions block DNA polymerases or prevent the progression of the replisome, arresting replication of the genome. Many DNA repair pathways exist; some respond to many types of lesions while others respond strictly to one, or a few related kinds of lesions. Oxidative lesions often affect single bases, sugars or phosphates within the DNA and efficient repair processes exist for many of these lesions. Oxidative stress conditions, however, can create a volume of these lesions great enough to impose a potential threat to genomic integrity. When the replisome encounters an unrepaired oxidative lesion, it may misread the base and polymerize incorrectly, resulting in a mutation introduced to the daughter strand. Oxidative lesions at high concentrations in the cell can lead to double strand breaks, mutagenesis, or cell death. Agents producing reactive ROS are inescapable - in humans, mitochondria release significant amounts of oxygen radicals into the cell, even under normal conditions. High intracellular ROS levels that generate DNA damage lead to increased mutation rate and cancer frequency in any replicating cell type (Rowe et al., 2008).

\section{The Role of Iron}

Iron acts as an important activating factor in many proteins in the cell. It plays a role in pathogen resistance (Nairz et al., 2010) and prominently influences the cellular response to oxidative stress. Iron of either charge catalyzes the Fenton and Haber-Weiss reactions, leading to the formation hydroxyl radicals (Haber and Weiss, 1932). In this respect iron homeostasis is dually critical for cellular metabolism - intracellular maintenance of iron concentration prevents the formation of excess oxygen radicals, while proteins from many functional domains depend on iron for activation. The process of iron sequestration in 
response to influx of oxygen radicals is well-characterized (Fillat, 2014; Carpenter \& Payne, 2014; Choi et al., 2001; Ricci et al., 2002; Farr and Kogoma, 1991; Lee and Helmann, 2006): E. coli responds to oxidative stress conditions by redox-dependent conformational changes in OxyR and PerR, transcription factors that induces transcription of ferritins, among other proteins responsible for oxygen radical quenching such as peroxidase and catalase (Horsburgh et al., 2001; Zámocký and Koller, 1999; Farr and Kogoma, 1991). Ferritins, like Dps, are proteins that sequester endogenous iron as well as functional iron stored in proteins. E. coli also disinhibits Fur in response to oxidative stress conditions, a regulon that encodes the transmembrane manganese importer MntH and several manganesedependent homologs to iron-dependent proteins, among other iron homeostasis and oxidative stress response proteins (Makui et al., 2000). This response seems to depict a compensatory relationship between the two metals - whereas the default metal, iron, is easily quenched by oxygen radicals, the alternative, manganese, is resistant (Archibald and Fridovich, 1981).

Although both iron and manganese are known to regulate the cellular response after oxidative challenges, and despite the importance of oxidative damage in mutagenesis and cancer, how divalent metals affect replication under these conditions has not been examined. Here we investigated the survival, recovery, and mutagenesis phenotypes exhibited by wildtype $E$. coli subjected to acute or chronic exposure to $10 \mathrm{mM} \mathrm{H}_{2} \mathrm{O}_{2}$ after growth in minimal medium supplemented with $200 \mu \mathrm{M}$ iron, manganese, or no metals.

We found that neither iron nor manganese availability affects the survival of wildtype cells exposed to chronic hydrogen peroxide. However, the presence of manganese was found to promote the rapid recovery of DNA synthesis after acute $\mathrm{H}_{2} \mathrm{O}_{2}$ exposure whereas 
iron did not promote the recovery of DNA synthesis. Finally, we found that the replication that occurred when manganese was present increased the mutation frequency, and that this mutagenic effect was found to be specific to oxidative damage. 


\section{Materials and Methods}

\section{Bacterial strains}

SR108 is a thyA36 deoC2 derivative of W3110 (Mellon and Hanawalt, 1989). All other strains used in this study were derived from SR108. Strains lacking recF (CL579) or polB $\operatorname{din} B$ umuDC (CL646) were constructed via P1 transduction and have been reported previously (Courcelle et al., 2003; Courcelle et al., 2006).

\section{Cell Culturing}

All experiments were performed in Davis medium (Davis, 1949) supplemented with $0.4 \%$ glucose, $0.2 \%$ casamino acids, and $10 \mu \mathrm{g} / \mathrm{mL}$ thymine (DGCthy) unless noted otherwise. Iron-supplemented DGCthy medium contained $200 \mu \mathrm{M} \mathrm{FeSO}{ }_{4} \cdot 7 \mathrm{H}_{2} \mathrm{O}$, while manganese-supplemented DGCthy medium contained $200 \mu \mathrm{M} \mathrm{MnCl}_{2}$. Cells were plated on Luria Bertani (LB) agar plates with $10 \mu \mathrm{g} / \mathrm{mL}$ thymine (LBthy) (Bertani, 1951; Sezonov et al., 2007).

\section{$\mathrm{H}_{2} \mathrm{O}_{2}$ survival assays}

Chronic exposure to $\mathrm{H}_{2} \mathrm{O}_{2}$ is here defined by the addition of $10 \mathrm{mM} \mathrm{H}_{2} \mathrm{O}_{2}$ to cell culture and leaving this concentration in culture for the duration of the experiment. Overnight cultures were diluted 1:100 in DGCthy medium supplemented with $200 \mu \mathrm{M} \mathrm{FeSO}{ }_{4} \cdot 7 \mathrm{H}_{2} \mathrm{O}$, $200 \mu \mathrm{M} \mathrm{MnCl} 2$, or without metals, and grown to $\mathrm{OD}_{600}$ of 0.4 in $37^{\circ}$ gyratory water baths. One pre-treatment aliquot of $0.1 \mathrm{~mL}$ was taken from each culture, before $\mathrm{H}_{2} \mathrm{O}_{2}$ addition to arrive at a final concentration of $10 \mathrm{mM} .0 .1 \mathrm{~mL}$ aliquots of each culture were removed at the time points indicated, and serially diluted in 10 fold increments. Each dilution was spotted onto LBthy plates in triplicate and allowed to incubate at $37^{\circ}$ overnight. Viable colonies were counted the following day. 


\section{Recovery of DNA synthesis}

Acute exposure to $\mathrm{H}_{2} \mathrm{O}_{2}$ is here defined by the addition of $10 \mathrm{mM} \mathrm{H}_{2} \mathrm{O}_{2}$ to cell culture for a five minute duration in $37^{\circ}$ gyratory water bath, at which point cells were then filtered on $0.45 \mu \mathrm{M}$ nitrocellulose membranes (Fisherbrand) and resuspended in fresh medium containing the indicated metal supplements. To measure the recovery of DNA synthesis, overnight cultures were diluted 1:100 in DGCthy medium supplemented with respective metals and $0.1 \mu \mathrm{Ci} / \mathrm{mL}^{14} \mathrm{C}$-thymine, then grown at $37^{\circ}$ in gyratory water baths. At $\mathrm{OD}_{600}$ of $0.4(\mathrm{t}=-5$ minutes $)$ cultures were split in half and $0.1 \mathrm{~mL}$ pre-treatment aliquots were removed from culture and placed in $5 \mathrm{~mL}$ PP tubes containing $0.5 \mu \mathrm{Ci} / \mathrm{mL}^{3} \mathrm{H}$-thymidine. 10 $\mathrm{mM} \mathrm{H} \mathrm{H}_{2} \mathrm{O}_{2}$ was added to half of the split cultures, while an equal volume of deionized water was added to the other half for control. After five minutes' incubation at $37^{\circ}$ cultures were filtered and resuspended as described above. Aliquots were taken and labeled with ${ }^{3} \mathrm{H}-$ thymidine (as before) immediately following resuspension ( $\mathrm{t}=0$ minutes) and at the indicated time points following. Samples were then filtered on glass fiber filters and radioactive labels were quantified using liquid scintillation.

\section{Mutagenesis}

Overnight cultures were diluted 1:100 in DGCthy medium supplemented with respective metals. At $\mathrm{OD}_{600}$ of $0.4(\mathrm{t}=-5$ minutes $)$ cultures were split in half, then either treated with $10 \mathrm{mM} \mathrm{H}_{2} \mathrm{O}_{2}$ or an equal volume of deionized water. After five minutes' incubation cultures were filtered and resuspended in fresh medium containing respective metals, then allowed to grow overnight. The following day, $0.1 \mathrm{~mL}$ from each culture was serially diluted in 10 fold increments and plated in triplicate $10 \mu \mathrm{L}$ spots on LBthy plates. An additional $1 \mathrm{~mL}$ or $0.1 \mathrm{~mL}$ was removed from each culture and plated on LBthy plates 
with $0.1 \mathrm{mg} / \mathrm{mL}$ rifampicin. Plates were incubated at $37^{\circ}$ overnight and colonies were counted the following day. 


\section{$\underline{\text { Results }}$}

\section{Replication recovery is stimulated in cells grown in manganese rich medium.}

An earlier study in the lab noted that the ability of cultures to recover replication after $\mathrm{H}_{2} \mathrm{O}_{2}$ challenge depended on the medium in which they were grown (Brandy Schalow, unpublished data). Whereas cultures grown in LB rapidly restored replication after a 5 minute incubation with $10 \mathrm{~mm} \mathrm{H}_{2} \mathrm{O}_{2}$, cultures grown in a supplemented Davis medium failed to recover replication after this same challenge. We noted that one significant difference between these two media is that LB medium contains significant amounts manganese and iron, whereas the supplemented Davis media had relatively low amounts of either metal (Table 1). To examine whether these metals affected the ability to recover from $\mathrm{H}_{2} \mathrm{O}_{2}$-induced DNA damage, we measured DNA synthesis and accumulation over time via radioactive DNA label following 5-minute incubation with and subsequent removal from $\mathrm{H}_{2} \mathrm{O}_{2}$ in Davis medium that was supplemented with either iron or manganese. To this end, cells grown in ${ }^{14} \mathrm{C}$-thymine medium containing no metal supplements, $200 \mu \mathrm{M}$ $\mathrm{FeSO}_{4} \cdot 7 \mathrm{H}_{2} \mathrm{O}$, or $200 \mu \mathrm{M} \mathrm{MnCl}_{2}$ were treated with $10 \mathrm{~mm} \mathrm{H}_{2} \mathrm{O}_{2}$ for 5 minutes before the drug was removed. Cultures were then allowed to recover for the duration of the experiment. At various times during the recovery period, duplicate aliquots from each culture were pulse labeled for 2 minutes with ${ }^{3} \mathrm{H}$-thymidine. The amount of ${ }^{14} \mathrm{C}$ and ${ }^{3} \mathrm{H}$ incorporated into the DNA was then determined at each time point to determine the relative rate of DNA synthesis ( ${ }^{3} \mathrm{H}$ incorporation) and total accumulation of DNA (14C incorporation) throughout the recovery period. Results showed that $\mathrm{H}_{2} \mathrm{O}_{2}$-exposed cultures in all conditions reduced DNA synthesis by nearly $1000 \mathrm{X}$ within the first 10 minutes following exposure. Cultures in either non-supplemented medium or iron-containing medium did not 
recover DNA synthesis for the duration of the experiment. In contrast, cultures supplemented with manganese recovered DNA synthesis around 20 to 30 minutes postresuspension. DNA accumulation was positively correlated with rate of DNA synthesis in all cases, indicating that the newly made DNA was stable and likely represents genomic replication rather than repair synthesis (Fig. 1). We interpret these results to indicate that manganese promotes the recovery of DNA synthesis after acute exposure to $\mathrm{H}_{2} \mathrm{O}_{2}$.

\section{Excess iron or manganese does not affect cell survival during chronic exposure} to $\mathrm{H}_{2} \mathrm{O}_{2}$.

To determine whether the manganese dependent DNA synthesis is beneficial or detrimental to survival in the presence of $\mathrm{H}_{2} \mathrm{O}_{2}$, wildtype cultures were grown in minimal medium containing no supplemented metals, $200 \mu \mathrm{M}$ iron, or $200 \mu \mathrm{M}$ manganese before 10 $\mathrm{mM} \mathrm{H}_{2} \mathrm{O}_{2}$ was added to the cultures. The fraction of cells surviving to form colonies was followed over time. Unexpectedly, we observed that the survival of cells from each metal condition was similar (Fig. 2) over time. From these results, we infer that the manganese dependent recovery of DNA synthesis following oxidative damage does not significantly improve survival of cells in culture.

\section{Manganese dependent recovery of DNA replication after oxidative challenge is} associated with increased mutagenesis.

The results above demonstrate that although manganese allows DNA replication to resume after $\mathrm{H}_{2} \mathrm{O}_{2}$ treatment, it does not affect viability. We next examined the fidelity of the replication occurring during recovery from oxidative challenge. To do this, we measured the frequency at which mutations arose conferring resistance to rifampicin after oxidative challenge. Replicating cultures containing no metal supplements, $200 \mu \mathrm{M}$ iron, or 
$200 \mu \mathrm{M}$ manganese were treated with either $10 \mathrm{mM} \mathrm{H}_{2} \mathrm{O}_{2}$ or were mock-treated for 5 minutes and then allowed to recover overnight. The following morning the number of viable and rifampicin resistant cells in each culture were determined. We found that manganese medium was associated with elevated levels of mutagenesis compared with media containing either iron or no additional metals (Fig. 3A). In medium containing no metal supplements, or in iron-supplemented medium, we observed that $\mathrm{H}_{2} \mathrm{O}_{2}$ challenge results in $\sim 3$ fold more rifampicin resistant mutations than mock treatment. By comparison, in the presence of manganese, the frequency of rifampicin resistant mutations increases by $\sim 10$ fold. As a control, we repeated this experiment treating the cells with 40 $\mathrm{J} / \mathrm{m}^{2} \mathrm{UVC}$ radiation instead of $\mathrm{H}_{2} \mathrm{O}_{2}$. In this case, the mutation rate increased $\sim 20$ fold in each of the medium conditions examined. Thus although UV irradiation was a more potent mutagen at this dose, no manganese-specific mutagenesis was observed. We interpret these results to indicate that the manganese associated mutagenesis we observed is specific to oxidative damage (Fig. 3B). Further, the mutagenesis observed correlates with the ability of manganese to promote the recovery of replication under these conditions.

\section{RecF is not responsible for the mutagenic recovery of replication in cultures}

\section{containing manganese, whereas mutation in polymerases II, IV and V modestly reduce the mutation frequency in cultures.}

RecF plays an important role in the recovery of replication when it is disrupted by UVinduced DNA damage (Courcelle et al., 1997; Courcelle et al., 2003). To examine if the manganese-dependent mutagenesis involved RecF after oxidative damage, we repeated the mutational assays described above repeated using a recF mutant. We reasoned that if the observed manganese-dependent recovery of replication depended on RecF, then the 
mutagenesis that was occurring would be diminished in the absence of RecF. However, we observed that the manganese dependent mutagenesis was unaffected in the absence of RecF and occurred at a rate similar to those seen in wild type cultures (Fig. 4). We interpret these observations to be consistent with the idea that the recovery promoted by manganese does not involve RecF.

Following specific forms of DNA damage in E.coli, mutagenesis requires specialized polymerases that are capable of replicating across DNA lesions with lower fidelity (Napolitano et al., 2000). E.coli contains three translesion DNA polymerases, Pol II, Pol IV, and Pol V (Napolitano et al., 2000). We hypothesized that the mutagenic replication occurring after $\mathrm{H}_{2} \mathrm{O}_{2}$ may be due to a manganese dependent translesion polymerase. To address this, we examined the frequency at which rifampicin resistance mutations arose as before, now in an E.coli strain that lacked polymerases II, IV and V for each metal condition. We found that the absence of translesion DNA polymerases only modestly reduced the manganese dependent mutagenesis that occurred following oxidative challenges (Fig. 5). We interpret these results to indicate that the translesion polymerases are partially responsible for the mutagenesis occurring after oxidative damage in the presence of manganese.

\section{$\underline{\text { Discussion }}$}

Taken together, the data would be consistent with a model wherein manganese restores function to iron dependent replication proteins that have been inactivated by oxidation. Manganese does not react with $\mathrm{H}_{2} \mathrm{O}_{2}$ and is capable of substituting for iron in several proteins which use iron as a cofactor (Anjem and Imlay, 2012). Using manganese as an alternative cofactor, we believe these proteins may be protected from inactivation. An 
alternative possibility would be that the presence of manganese activates the transcription of proteins that promote the recovery of replication after $\mathrm{H}_{2} \mathrm{O}_{2}$. This possibility seems less likely, given the resistance of $r e c F$ mutants to $\mathrm{H}_{2} \mathrm{O}_{2}$. To the best of our knowledge, recF mutants are required for the recovery of replication whenever it is disrupted by DNA lesions (Courcelle et al., 1997; Courcelle et al., 2003; Courcelle and Hanawalt, 2003). Yet, we observe that replication arrests and recovers similarly to wild type cells in the $\operatorname{rec} F$ mutants. This argues that the arrest of replication is caused not by DNA lesions, but more likely because iron dependent replication proteins have been inactivated by the $\mathrm{H}_{2} \mathrm{O}_{2}$ treatment. Thus the data implicate a post-translational response. With manganese present, replication resumes at 20 minutes after removal. This would be consistent with the idea that manganese can substitute for the iron in these inactivated proteins, allowing replication to be restored.

Candidates that may be responsible for this phenotype include iron-dependent enzymes such as glycosylases, helicases, and cytochromes. During the iron sequestration step of the oxidative stress response in E. coli, iron may be stripped from any of these enzymes, resulting in either non-function or function through replacement by a similar divalent metal (such as manganese). Glycosylases are essential to the base excision repair pathway, the main method by which oxidative lesions are removed from the chromosome. Like other proteins of the oxidative stress response, several glycosylases are activated by the oxidation of iron in Fe-S clusters (Outten, 2007). If this iron was sequestered without replacement by another divalent metal, there could be no base excision repair, potentially delaying the resumption of DNA replication. Previous studies have shown, however, that deletion of glycosylases does not affect the ability of $E$. coli to resume DNA replication after 
oxidative challenge (Schalow et al., 2011). This suggests that the manganese dependent resumption of replication does not occur through glycosylase activity.

Helicases have a more direct role in DNA synthesis. Specifically, DinG is a damage inducible helicase in E. coli with a Fe-S cluster that serves to activate the enzyme upon oxidation (Ren et al., 2009). It is possible that in the absence of iron, DinG cannot be activated, and so is incapable of unwinding DNA for replication during periods of oxidative stress. Manganese may serve to substitute for iron in this case, enabling the activity of DinG and the processivity of DNA replication through oxidative stress conditions. The helicase normally implicated in resumption of DNA replication after DNA damage, RecQ (Courcelle and Hanawalt, 1999) has not been reported to contain a Fe-S cluster.

Cytochromes are hemeproteins responsible for ATP production. DNA replication is an ATP-dependent process, and so is limited by the availability of ATP. If cytochromes are inactivated by the sequestration of their iron cofactors during periods of oxidative stress, then the available ATP pool in the cell would drop. This may result in the cell's inability to resume DNA replication in a timely manner. Under manganese rich conditions, however, the missing iron cofactor might be replaced by manganese, allowing for the restoration of ATP synthesis.

It has been observed by Mansour et al that iron complexes with ATP under iron rich conditions (Mansour et al., 1985). Given the similar conformations of iron and manganese, it is possible that manganese may also complex with NTPs. Additionally, it is speculated by Mansour et al that such complexes may alter the available pool of nucleotide triphosphates (NTPs). Incorporation of these modified NTPs by Pol I or Pol III may contribute to the 
mutagenic phenotype observed during manganese dependent DNA replication after oxidative challenge. 


\section{Tables}

\begin{tabular}{|c|c|c|c|c|c|c|c|c|}
\hline Sample ID & Mg [mg/L] & $\mathbf{C r}[\mathbf{u g} / \mathbf{L}]$ & Mn [ug/L] & Fe [ug/L] & Ni [ug/L] & Cu [ug/L] & Zn [ug/L] & $\mathrm{Pb}[\mathrm{ug} / \mathbf{L}]$ \\
\hline DI Water & 0.00 & $<0.024$ & 0.474 & 0.33 & 0.032 & 0.866 & 6.33 & 0.417 \\
\hline Davis & 115.93 & 29.9916 & 62.817 & 174.35 & 13.903 & 2.757 & 352.13 & 0.275 \\
\hline Glucose & 0.03 & 0.1800 & 0.451 & 2.53 & 0.154 & 1.335 & 5.09 & 0.115 \\
\hline Casaminos & 1.74 & 20.5225 & 13.223 & 266.33 & 18.534 & 23.010 & 1066.49 & 0.149 \\
\hline Thymine & 0.02 & 0.0930 & 0.844 & 1.08 & 0.277 & 12.084 & 6.03 & 0.061 \\
\hline DGCthy & $\mathbf{9 . 5 3}$ & $\mathbf{3 . 4 7 6 9}$ & $\mathbf{6 . 4 3 0}$ & $\mathbf{2 7 . 3 5}$ & $\mathbf{2 . 3 4 1}$ & $\mathbf{4 . 3 0 1}$ & $\mathbf{7 6 . 3 9}$ & $\mathbf{0 . 1 8 6}$ \\
\hline LB & $\mathbf{1 . 9 9}$ & $\mathbf{1 6 . 0 0 5 8}$ & $\mathbf{1 0 . 1 1 8}$ & $\mathbf{2 4 1 . 6 4}$ & $\mathbf{3 . 8 0 8}$ & $\mathbf{1 4 . 7 2 9}$ & $\mathbf{5 3 9 . 8 3}$ & $\mathbf{0 . 2 8 4}$ \\
\hline LB (no tryptone) & 0.82 & 1.7345 & 5.966 & 133.79 & 1.028 & 20.260 & 332.43 & 0.748 \\
\hline Tryptone & 64.46 & 554.2679 & 342.399 & 6233.44 & 89.966 & 357.831 & 13789.66 & 1.874 \\
\hline Yeast Extract & 40.51 & 30.8449 & 263.697 & 4864.50 & 31.973 & 314.416 & 18489.87 & 1.736 \\
\hline
\end{tabular}

Table 1. Concentrations of metals in components of DGCthy and LB media (Analysis from Oregon Health \& Science University Core Services) 


\section{Figures}

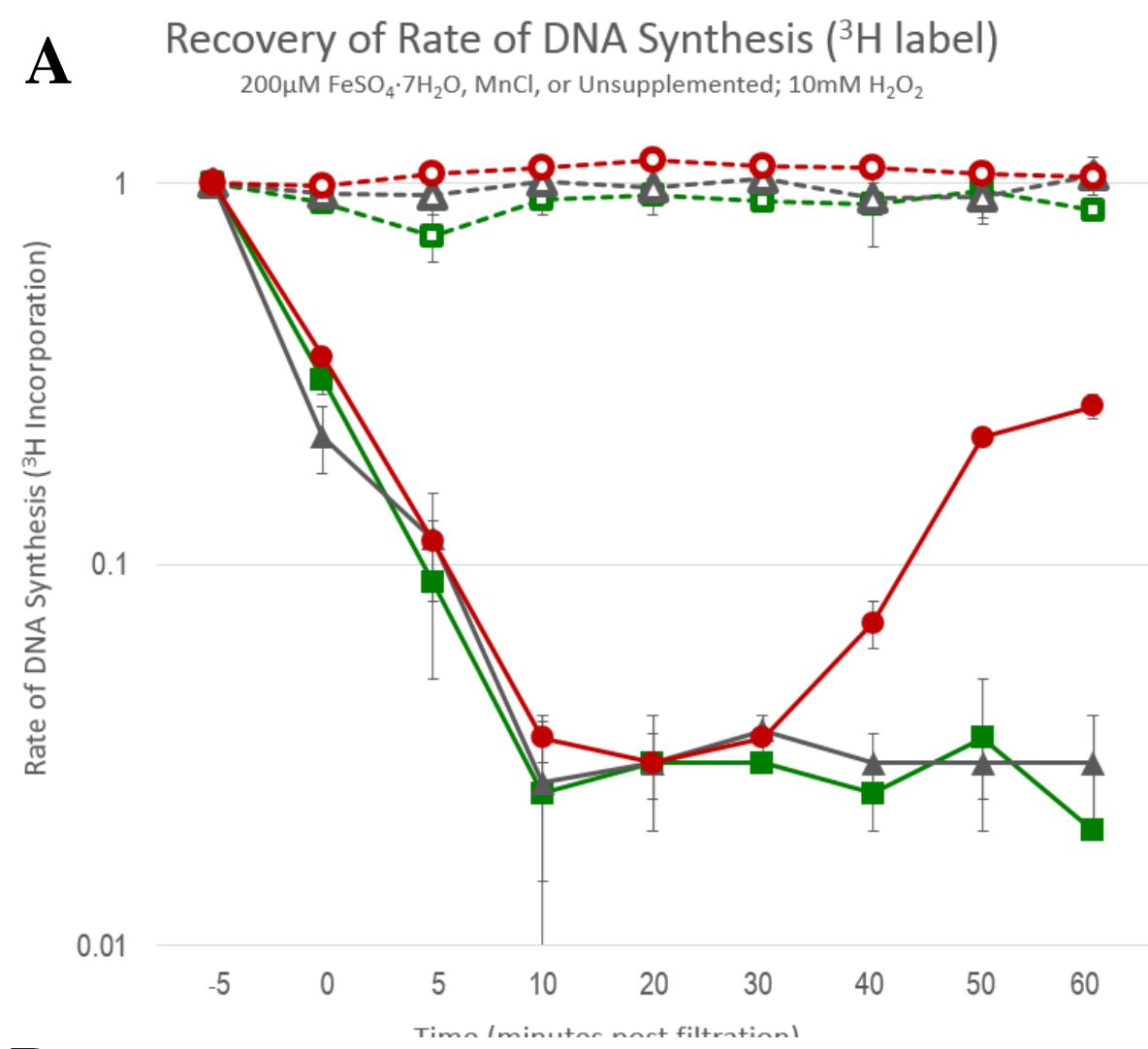

Figure 1. Replication recovery is stimulated in cells grown in manganese medium. ${ }^{14} \mathrm{C}$ thymine prelabeled cultures were treated with $10 \mathrm{mM} \mathrm{H}_{2} \mathrm{O}_{2}$. Between -5 and 0 minutes cells were incubating with $10 \mathrm{mM}$ $\mathrm{H}_{2} \mathrm{O}_{2}$. At $\mathrm{t}=0$ cells were filtered and resuspended in fresh medium containing ${ }^{14} \mathrm{C}$-thymine and the respective metal.

Aliquots were then pulse-labeled with ${ }^{3} \mathrm{H}$-thymidine for 2 minutes before cells were lysed and the amount of radioactivity incorporated into the DNA was determined. (A) Relative ${ }^{3} \mathrm{H}$ incorporated into DNA/2 minutes pulse at each time point in the recovery period is plotted. (B) Total ${ }^{14} \mathrm{C}$ incorporated into DNA at each time point in the recovery period is plotted. (Open shapes) mock-treated controls, (closed shapes) $\mathrm{H}_{2} \mathrm{O}_{2}$-treated. (Red) manganese. (Green) iron. (Grey) no additional metals. 


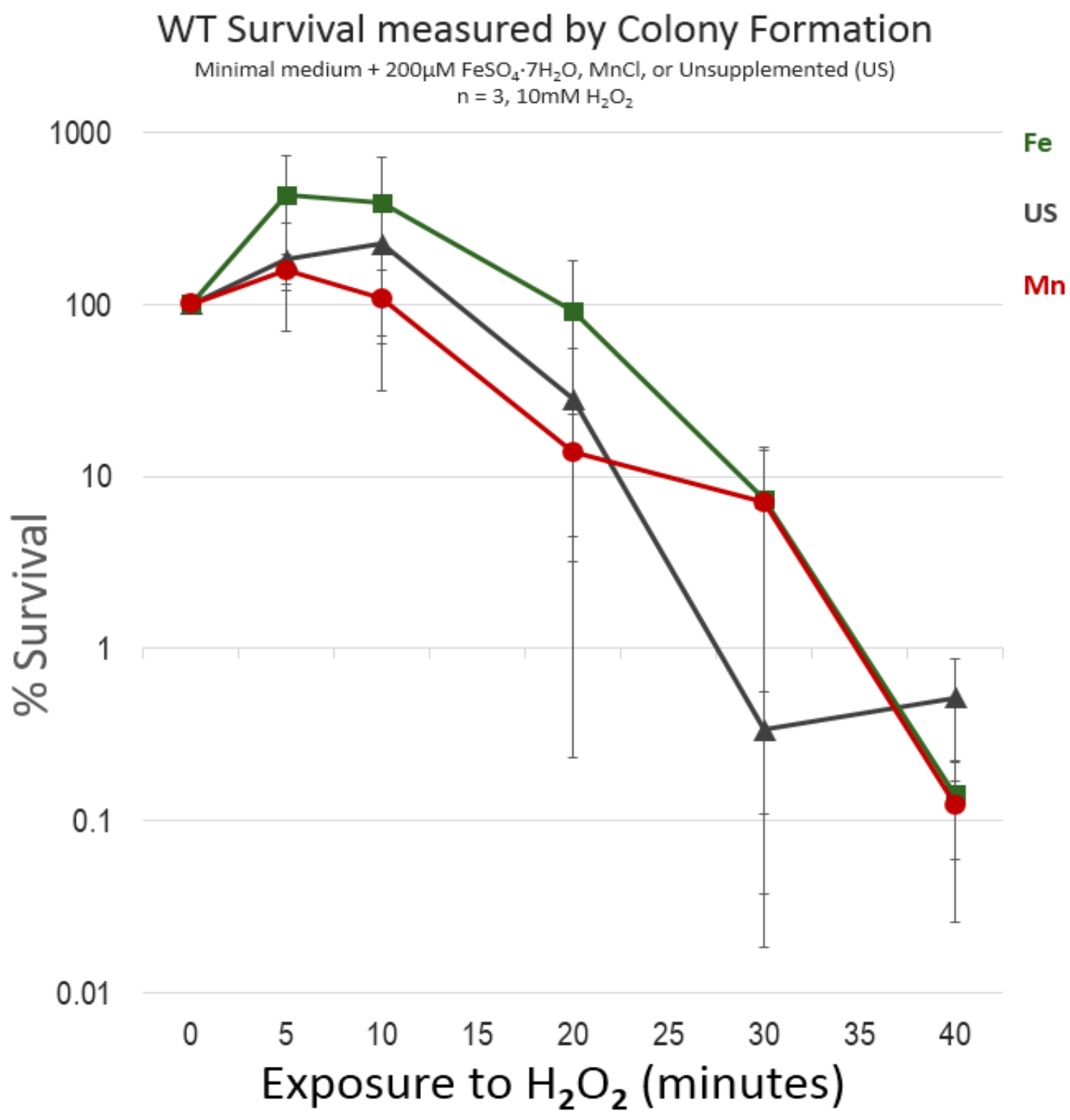

Figure 2. Neither iron nor manganese affects the survival of wild type cultures during chronic exposure to $\mathrm{H}_{2} \mathrm{O}_{2}$. The percentage of cells surviving to form colonies following exposure to $\mathrm{H}_{2} \mathrm{O}_{2}$ for the indicated amount of time is plotted. (Red) cultures grown in manganese-rich conditions. (Green) cultures grown in iron-rich conditions. (Black) cultures grown without added metals. $10 \mathrm{mM} \mathrm{H}_{2} \mathrm{O}_{2}$ was added to cultures and aliquots were taken at the time points indicated on the $\mathrm{X}$ axis, serially diluted, then plated in triplicate $10 \mu \mathrm{l}$ spots and allowed to grow overnight. Colonies were counted the following day. 


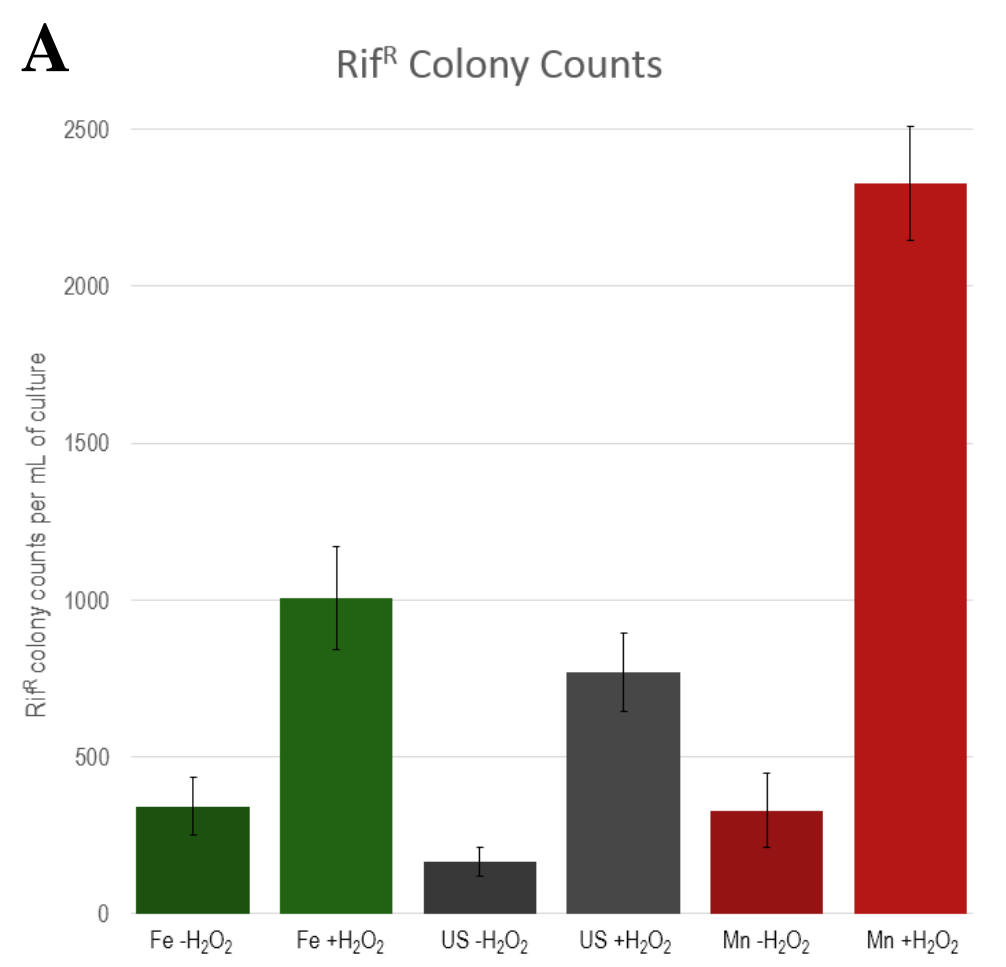

B

100000

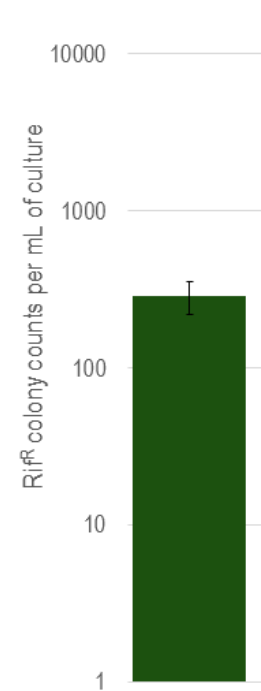

Fe -UV

\section{Rif $^{\mathrm{R}}$ Colony Counts (UV)}

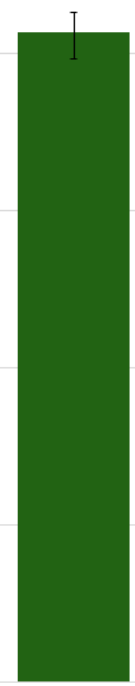

$\mathrm{Fe}+\mathrm{UV}$

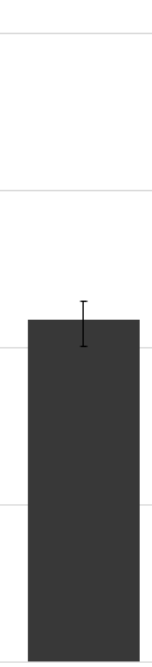

US -UV

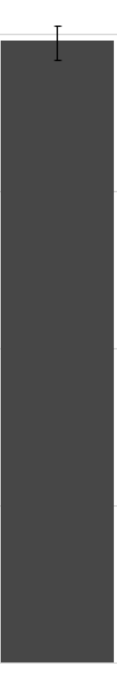

US +UV

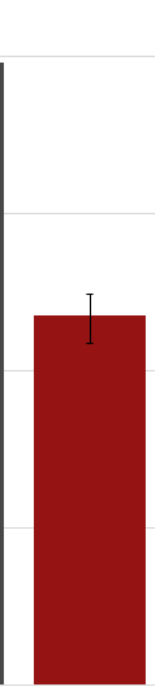

Mn -UV Mn+UV
Figure 3. The manganese-dependent, recovery of replication is mutagenic and specific to oxidative damage. (A) Cultures grown in manganese, iron, or unsupplemented medium were either mock-treated or exposed to $10 \mathrm{~mm} \mathrm{H}_{2} \mathrm{O}_{2}$ for 5 minutes and allowed to recover overnight. The number of cells $/ \mathrm{mL}$ of culture that mutated and could form Rif ${ }^{\mathrm{R}}$ colonies were then determined. (B) Unlike oxidative challenges, no manganesedependent mutagenesis is observed when cultures are challenged with UV radiation. Cultures grown in manganese, iron, or unsupplemented medium were either mock-treated or irradiated with $25 \mathrm{~J} / \mathrm{m}^{2}$ UVC and allowed to recover overnight. The number of cells/mL of culture that mutated and could form Rif ${ }^{\mathrm{R}}$ colonies were then determined. 


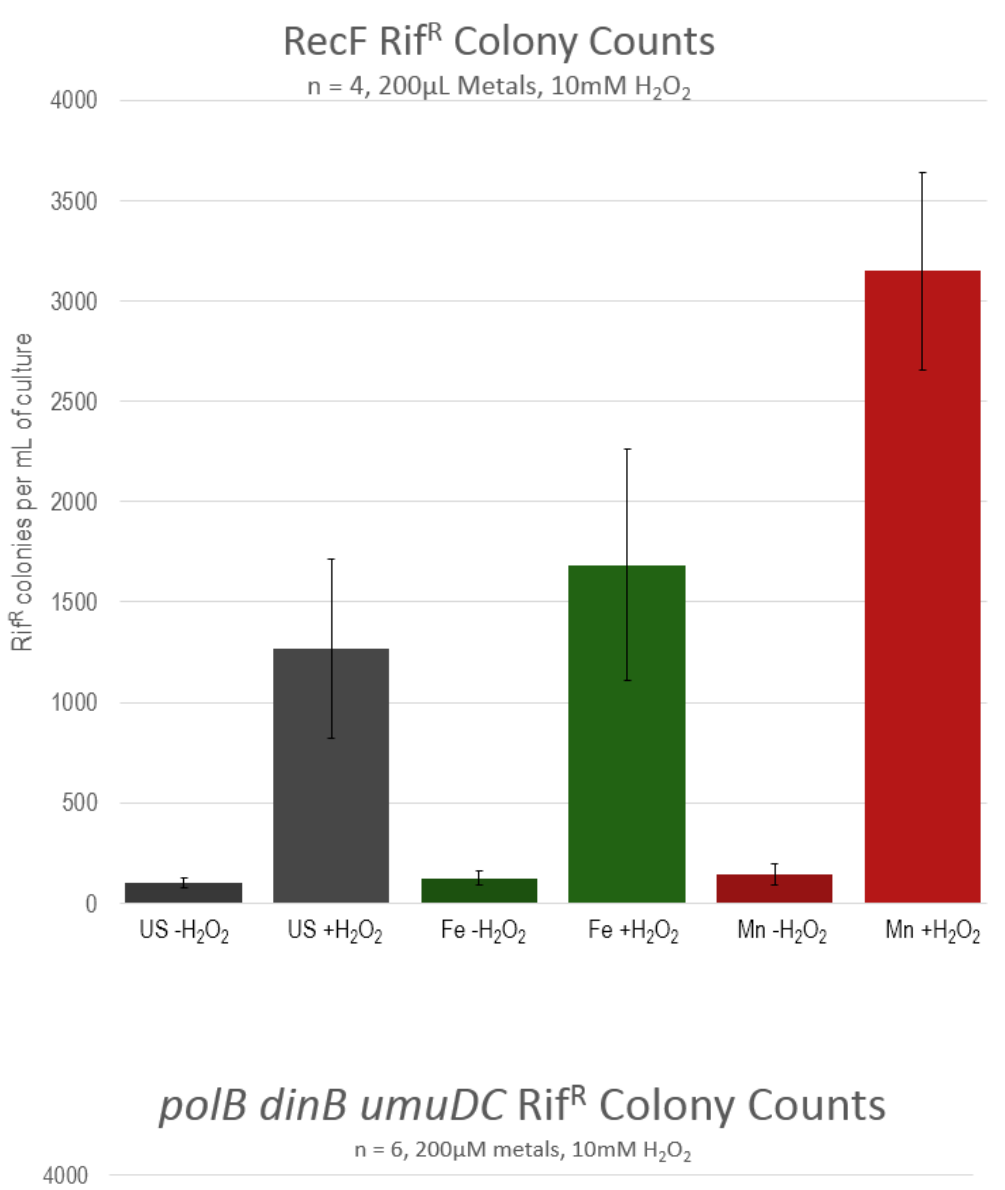

$3500-$

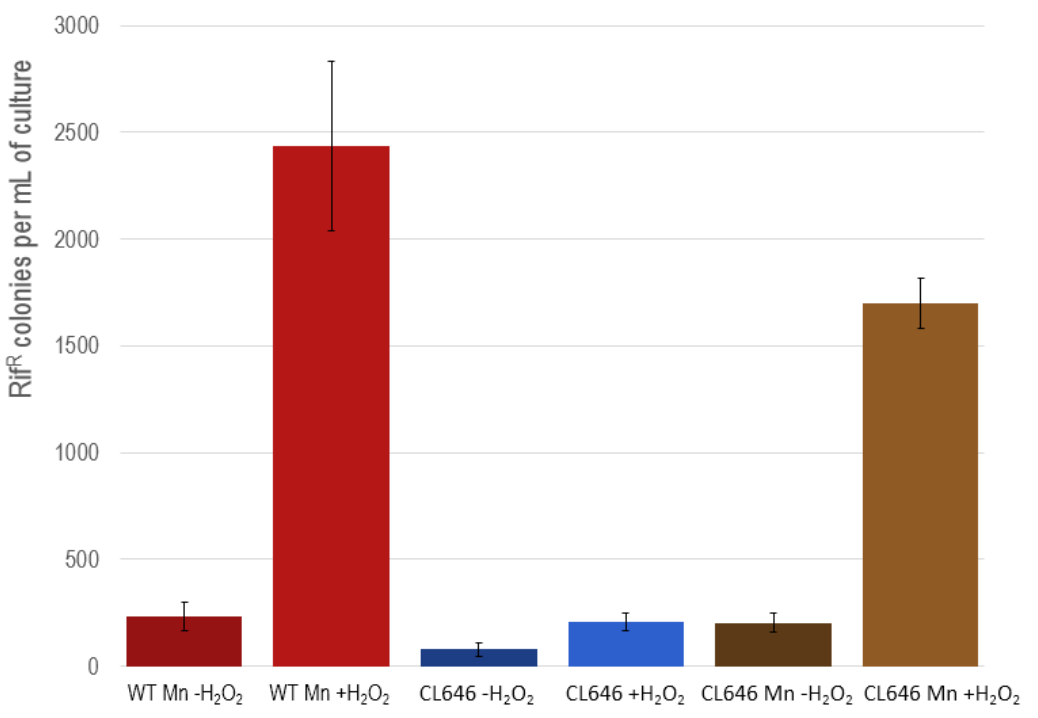

Figure 4. The absence of RecF does not affect the mutagenesis that occurs during the manganesedependent recovery of replication from oxidative challenges. $\operatorname{Rec} F$ cultures were grown, exposed and allowed to recover as in Fig 3. Red bars indicate manganesesupplemented cultures. Green bars indicate iron-supplemented cultures. Dark grey bars indicate unsupplemented cultures.

Figure 5. The absence of polymerases II, IV and V modestly reduces the mutagenesis that occurs following oxidative challenge in the presence of manganese. PolB dinB umuCD cultures were grown, exposed and allowed to recover as in Fig 3. Red bars indicate manganesesupplemented wildtype cultures. Blue bars indicate unsupplemented cultures lacking translesion polymerases. Brown bars indicate manganese supplemented cultures lacking translesion polymerases. 


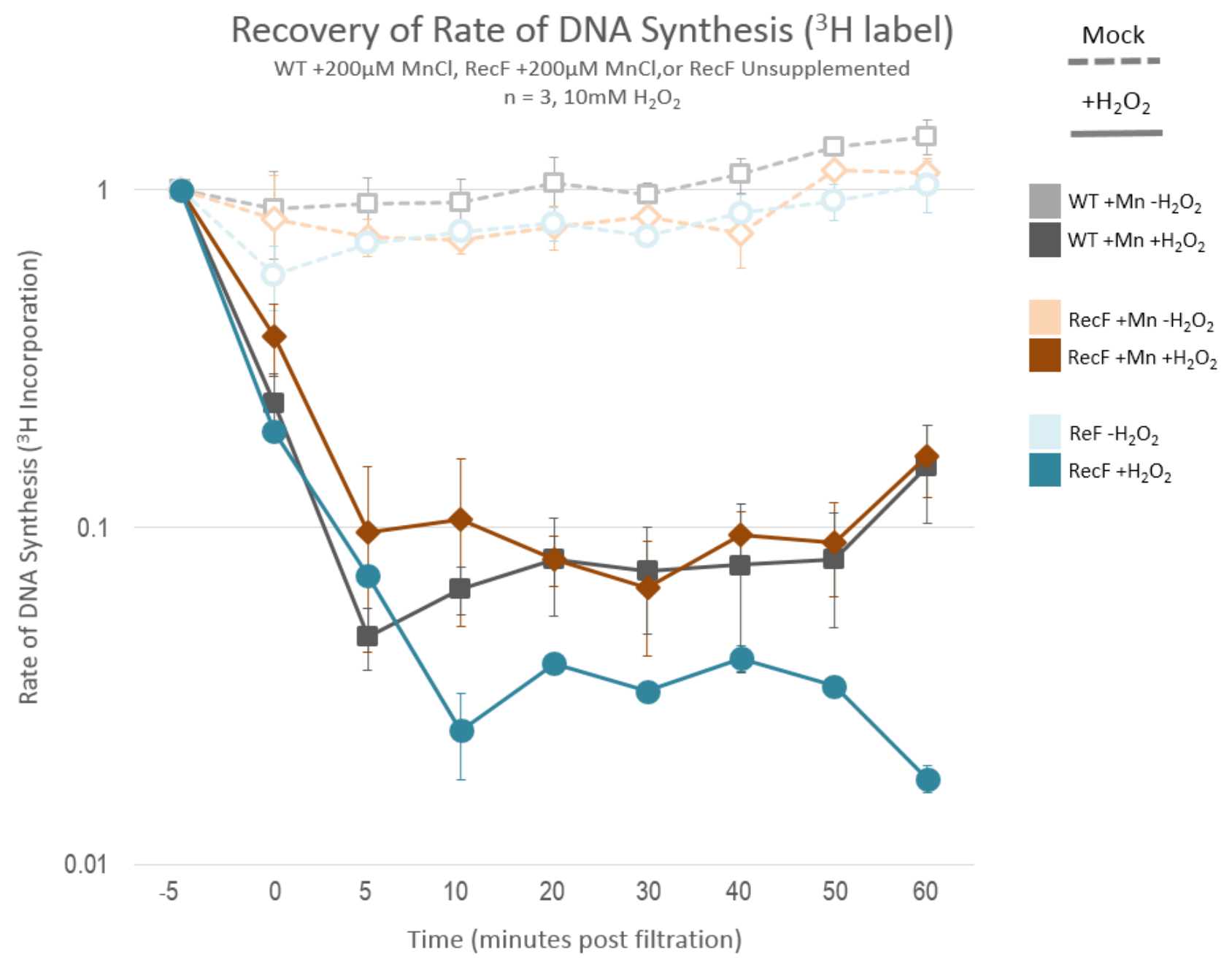

Figure 5. Mn-dependent replication recovery phenotype is not affected by the lack of RecF. The assay described in figure $2 \mathrm{~A}$ is here repeated using cells lacking RecF. Open shapes with dashed lines indicate untreated controls, while closed shapes with solid lines indicate $\mathrm{H}_{2} \mathrm{O}_{2}$-treated cells. Brown and black indicate cells grown in manganese-rich conditions. Blue indicates cells grown without additional metals. 


\section{Acknowledgements}

This work was made possible by the NIH/National Institute of Environmental Health Sciences Grant R15ES025953 and NSF Grant MCB1518142. 


\section{References}

1. Fridovich, Irwin. "Superoxide Radical and Superoxide Dismutases." Annual Review of Biochemistry 64, no. 1 (1995): 97-112.

2. Lindahl, T., and R. D. Wood. "Quality Control by DNA Repair.” Science (New York, N.Y.) 286, no. 5446 (December 3, 1999): 1897-1905.

3. Semenenko, V. A., and R. D. Stewart. "Monte Carlo Simulation of Base and Nucleotide Excision Repair of Clustered DNA Damage Sites. II. Comparisons of Model Predictions to Measured Data." Radiation Research 164, no. 2 (August 2005): 194-201.

4. Semenenko, V. A., R. D. Stewart, and E. J. Ackerman. "Monte Carlo Simulation of Base and Nucleotide Excision Repair of Clustered DNA Damage Sites. I. Model Properties and Predicted Trends." Radiation Research 164, no. 2 (August 2005): 180-93.

5. Rowe, Lori A., Natalya Degtyareva, and Paul W. Doetsch. "DNA Damage-induced Reactive Oxygen Species (ROS) Stress Response in Saccharomyces Cerevisiae." Free Radical Biology \& Medicine 45, no. 8 (October 15, 2008): 1167-77.

6. Nairz, Manfred, Andrea Schroll, Thomas Sonnweber, and Günter Weiss. "The Struggle for Iron - a Metal at the Host-pathogen Interface.” Cellular Microbiology 12, no. 12 (December 1, 2010): 1691-1702.

7. Fillat, María F. "The FUR (ferric Uptake Regulator) Superfamily: Diversity and Versatility of Key Transcriptional Regulators." Archives of Biochemistry and Biophysics 546 (March 15, 2014): 41-52.

8. Carpenter, Chandra, and Shelley M. Payne. "Regulation of Iron Transport Systems in Enterobacteriaceae in Response to Oxygen and Iron Availability.” Journal of Inorganic Biochemistry 133 (April 2014): 110-17.

9. Choi, H., S. Kim, P. Mukhopadhyay, S. Cho, J. Woo, G. Storz, and S. E. Ryu. "Structural Basis of the Redox Switch in the OxyR Transcription Factor." Cell 105, no. 1 (April 6, 2001): 103-13.

10. Ricci, Susanna, Robert Janulczyk, and Lars Björck. "The Regulator PerR Is Involved in Oxidative Stress Response and Iron Homeostasis and Is Necessary for Full Virulence of Streptococcus Pyogenes." Infection and Immunity 70, no. 9 (September 2002): 4968-76.

11. Farr, S B, and T Kogoma. "Oxidative Stress Responses in Escherichia Coli and Salmonella Typhimurium." Microbiological Reviews 55, no. 4 (December 1991): 561-85.

12. Lee, Jin-Won, and John D. Helmann. "The PerR Transcription Factor Senses H2O2 by Metal-catalysed Histidine Oxidation." Nature 440, no. 7082 (March 16, 2006): 363-67.

13. Courcelle, Justin, David J. Crowley, and Philip C. Hanawalt. "Recovery of DNA Replication in UV-Irradiated Escherichia Coli Requires Both Excision Repair and RecF Protein Function.” Journal of Bacteriology 181, no. 3 (February 1999): 916-22.

14. Courcelle, Justin, Catherine Carswell-Crumpton, and Philip C. Hanawalt. "recF and recR Are Required for the Resumption of Replication at DNA Replication Forks in Escherichia Coli." Proceedings of the National Academy of Sciences 94, no. 8 (April 15, 1997): 3

15. Mansour, A.N., Thompson, C., Thiel, E.C., Chasteen, D., and Sayers, D.E. "Fe(III).ATP complexes. Models for ferritin and other polynuclear iron complexes with phosphate." Journal of Biological Chemistry 260 (July 1985): $7975-7979$.

16. Ren, Binbin, Xuewu Duan, and Huangen Ding. "Redox Control of the DNA Damage-inducible Protein DinG Helicase Activity via Its Iron-Sulfur Cluster.” The Journal of Biological Chemistry 284, no. 8 (February 20, 2009): 4829-35.

17. Anjem, Adil and Imlay, J.A. "Mononuclear Iron Enzymes are Primary Targets of Hydrogen Peroxide Stress." The Journal of Biological Chemistry 287, no. 19 (May 4, 2012): 15544 - 15556.

18. Horsburgh, M.J., Clements, M.O., Crossley, H., Ingham, E., Foster, S.J. "PerR Controls Oxidative Stress Resistance and Iron Storage Proteins and Is Required for Virulence in Staphylococcus aureus." Infection and Immunity 69, no. 6 (June 2001): $3744-3754$.

19. Haber F., Weiss J. "Über die Katalyse des Hydroperoxydes (On the catalysis of hydroperoxide)." Naturwissenschaften 20, no. 51 (1932): 948-950).

20. Zámocký, Marcel, and Franz Koller. "Understanding the Structure and Function of Catalases: Clues from Molecular Evolution and in Vitro Mutagenesis." Progress in Biophysics and Molecular Biology 72, no. 1 (June 1, 1999): 19-66.

21. Makui, Hortence, Eva Roig, Stewart T. Cole, John D. Helmann, Philippe Gros, and Mathieu F. M. Cellier. "Identification of the Escherichia Coli K-12 Nramp Orthologue (MntH) as a Selective Divalent Metal Ion Transporter." Molecular Microbiology 35, no. 5 (March 1, 2000): 1065-78. 
22. Archibald, F. S., and I. Fridovich. "Manganese, Superoxide Dismutase, and Oxygen Tolerance in Some Lactic Acid Bacteria." Journal of Bacteriology 146, no. 3 (June 1981): 928-36.

23. Outten, F. Wayne. "Iron-Sulfur Clusters as Oxygen-Responsive Molecular Switches." Nature Chemical Biology 3 , no. 4 (April 2007): 206-7.

24. Courcelle, Justin, Janet R. Donaldson, Kin-Hoe Chow, and Charmain T. Courcelle. "DNA Damage-Induced Replication Fork Regression and Processing in Escherichia Coli." Science 299, no. 5609 (January 23, 2003).

25. Courcelle, Charmain T., Kin-Hoe Chow, Andrew Casey, and Justin Courcelle. "Nascent DNA Processing by RecJ Favors Lesion Repair over Translesion Synthesis at Arrested Replication Forks in Escherichia Coli." Proceedings of the National Academy of Sciences 103, no. 24 (June 13, 2006): 9154-59.

26. Bertani, G. "Studies on Lysogenesis I." Journal of Bacteriology 62, no. 3 (September 1951): 293-300.

27. Sezonov, Guennadi, Danièle Joseleau-Petit, and Richard D'Ari. "Escherichia Coli Physiology in Luria-Bertani Broth.” Journal of Bacteriology 189, no. 23 (December 2007): 8746-49.

28. Courcelle, Justin, and Philip C. Hanawalt. "RecA-Dependent Recovery of Arrested DNA Replication Forks." Annual Review of Genetics 37 (2003): 611-46.

29. Davis, Bernard D. "The Isolation of Biochemically Deficient Mutants of Bacteria by Means of Penicillin." Proceedings of the National Academy of Sciences 35, no. 1 (January 1949): 1-10.

30. Schalow, Brandy J., Charmain T Courcelle, and Justin Courcelle. "Escherichia Coli Fpg Glycosylase Is Nonrendundant and Required for the Rapid Global Repair of Oxidized Purine and Pyrimidine Damage In Vivo." Journal of Molecular Biology 410, no. 2 (July 8, 2011): 183-93.

31. Courcelle, J., and P. C. Hanawalt. "RecQ and RecJ Process Blocked Replication Forks prior to the Resumption of Replication in UV-Irradiated Escherichia Coli." Molecular and General Genetics 262, no. 3 (November 1, 1999): 543-51.

32. Napolitano, R., R. Janel-Bintz, J. Wagner, and R.P.P. Fuchs. "All Three SOS-Inducible DNA Polymerases (Pol II, Pol IV and Pol V) Are Involved in Induced Mutagenesis." The EMBO Journal 19, no. 22 (November 15, 2000): 6259-65. 